\title{
Oxygen Consumption and Heat Balance in the Cot-nursed Baby
}

\author{
E. N. HEY and BRIDGET O'CONNELL \\ From the Neonatal Research Group, The London Hospital Medical College, London
}

\begin{abstract}
Hey, E. N., and O'Connell, B. (1970). Archives of Disease in Childhood, 45, 335. Oxygen consumption and heat balance in the cot-nursed baby. Oxygen consumption and heat balance have been studied in 42 clothed babies under varied environmental temperature conditions. The information obtained has made it possible to compare the thermal environment provided by an incubator with that provided by an ordinary nursery cot. Some of the merits of cots and incubators are contrasted.

Resistance to heat loss in a naked newborn baby lying on a mattress in a moderately humid draught-free room is approximately 1 ' $c l o$ ' unit. Provision of a vest, napkin, and long nightdress increases this resistance to about $2 \cdot 3$ units, while wrapping the clothed baby in a flannelette sheet and covering it with 2 layers of cotton blanket increases the total resistance to $2 \cdot 9$ clo units.

A draught-free environment of $24^{\circ} \mathrm{C}$. $\left(75^{\circ} \mathrm{F}\right.$.) is necessary to provide completely neutral thermal conditions for most cot-nursed babies insulated against heat loss with clothes and blankets in the first month of life, while a room temperature of up to $29{ }^{\circ} \mathrm{C}$. $\left(85^{\circ} \mathrm{F}\right.$.) may be necessary to ensure comparable conditions for a baby weighing less than $1 \frac{1}{2} \mathrm{~kg}$. during much of the first week of life.
\end{abstract}

Everyone recognizes that babies need to be kept warm. It is, however, difficult to judge when optimum conditions have been achieved. Measurement of body temperature alone largely fails to indicate whether a baby is being subjected to thermal stress: it can only alert us to situations in which the thermal stress has been so severe that the baby's normal thermoregulatory mechanisms have been at least partially overpowered.

Recognition of this problem has stimulated a lot of research in the past 10 years, but the work has been directed almost exclusively to the study of heat balance in the naked baby. Numerous studies of the warmth provided by incubators have now appeared, but we have remarkably little idea how this environment compares with that provided by an ordinary nursery cot.

Budin, in Paris, was teaching the importance of adequate environmental warmth in the care of small babies in 1900: he kept all his babies clothed and covered with light blankets, but came to the conclusion that this was not, in itself, enough for

Received 20 November 1969. the smaller babies. He therefore extended and popularized the idea of nursing the more vulnerable babies fully clothed in specially constructed incubators. Clinical experience led him to recommend an air temperature of $30^{\circ} \mathrm{C}$. in these incubators for the smallest ( $1 \mathrm{~kg}$.) babies, and a temperature of $25^{\circ} \mathrm{C}$. for most of the other small babies at risk.

Thirty years later Blackfan and Yaglou (1933) reached much the same conclusion about optimum air temperature after four years of clinical experience with the new air-conditioned nurseries in Boston. Little new information seems to have accumulated since then, and no detailed study of heat balance in the cot-nursed baby ever appears to have been undertaken. We have now studied this problem with the aid of a specially constructed metabolic chamber (Fig. 1), using the methods and techniques developed by Hey and Katz (1970) during the parallel study of heat balance in the naked baby.

\section{Methods}

Oxygen consumption and heat balance have been investigated in a draught-free environment of average 


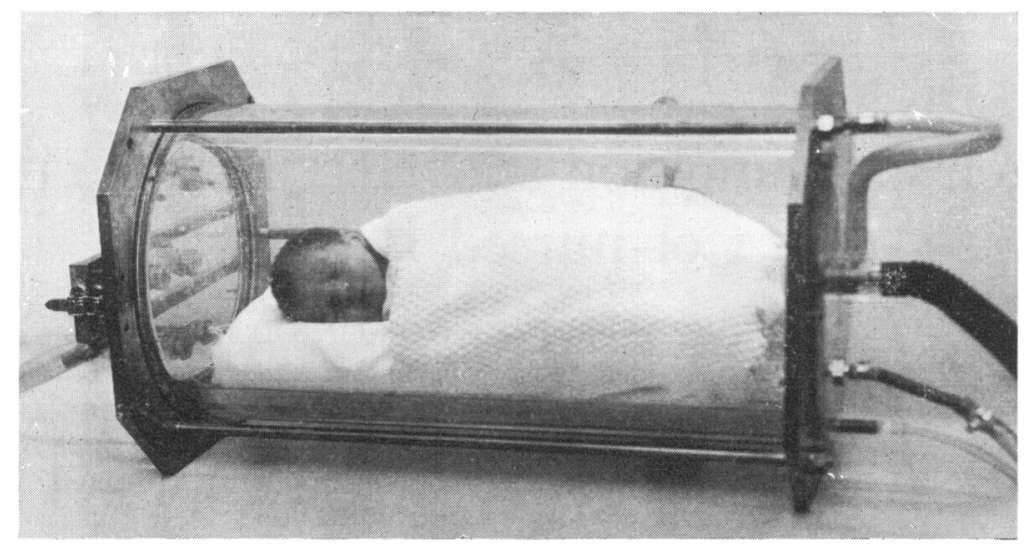

FIG. 1.-The metabolic chamber used for the majority of the studies.

humidity at a number of different operative temperatures using a combination of direct and indirect calorimetry. 42 healthy premature and full-term infants of known gestation born in The London Hospital have been studied with the consent of their parents. Details of the methods employed have been given elsewhere (Hey, Katz, and O'Connell, 1970). Rectal temperature was between 36.4 and $37 \cdot 6^{\circ} \mathrm{C}$. Oxygen consumption was expressed as $\mathrm{ml} . / \mathrm{kg} . \mathrm{min}$. after reduction to S.T.P. (dry), while heat production, storage, and loss were calculated in Calories per square metre of total skin surface per hour (kcal./m. ${ }^{2} \mathrm{hr}$.). The warmth of the clothing and bedding was judged by its insulating property, where 1 ' $c l o$ ' unit is equivalent to an insulation of $0 \cdot 18{ }^{\circ} \mathrm{C} . \mathrm{m} .^{2} \mathrm{hr} . / \mathrm{kcal}$. (Gagge, Burton, and Bazett, 1941).

Environmental conditions. Care was taken to make the experimental environment comparable with that normally encountered on hospital wards. The environment near the baby was free of any draughts or forced convection currents; natural convection currents of warm air accounted for an air speed of between 4 and $5 \mathrm{~cm}$./ $\mathrm{sec}$. close to the mattress and bedding. Humidity was controlled so that the air was always between 30 and $70 \%$ saturated with water vapour; this is similar to the range of relative humidity normally encountered in British hospital buildings. Air temperature and mean radiant temperature never differed from each other by more than $1.5^{\circ} \mathrm{C}$. and a weighted mean of the two was employed to define the actual operative temperature. This operative temperature is, in fact, very similar to the temperature that is recorded by a globe thermometer; for simplicity it will be referred to as 'room temperature'.

Metabolic chamber. For the majority of the studies reported here the conditions provided by a nursery cot were simulated in a larger version of the metabolic chamber used by Hill and Rahimtulla (1965) and Hey (1969). The enlarged chamber (Fig. 1) consisted of a water-jacketed Perspex cylinder $25 \mathrm{~cm}$. in internal diameter and $60 \mathrm{~cm}$. long, with thin Perspex baffles inside the end walls to deflect the gas flow and help maintain an even radiant temperature. The babies lay supine within the chamber on a plastic foam mattress $5 \mathrm{~cm}$., thick. The clothing and bedding were varied as described below. Measurements of oxygen consumption and heat balance were made over a period of 20 minutes at each temperature, and each baby was studied at 6 different operative temperatures over a period of 2 days. Care was taken to ensure that equilibrium conditions had been established before measurements were begun: a minimum period of half an hour was allowed after any change of temperature, and the operative temperature was never changed by more than $3^{\circ} \mathrm{C}$. at a time. On 22 occasions measurements were begun 30 minutes after a $3{ }^{\circ} \mathrm{C}$. change of chamber waterjacket temperature and continued for a period of 40 minutes. There were no consistent differences between the results obtained during the first and the second halves of these extended periods of measurement.

Various precautions were taken to ensure that total evaporative water loss was correctly estimated. The foam mattress in the chamber was covered with a thin sheet of waterproof plastic. Absolute humidity was maintained at $10 \mathrm{~mm}$. $\mathrm{Hg}$, and the air in the chamber was therefore between $30 \%$ and $70 \%$ saturated depending on air temperature. All clothing and bedding was kept in an atmosphere of $10 \mathrm{~mm}$. $\mathrm{Hg}$ for at least a day before use to ensure that its moisture content was stable. Readings were taken before and after each study, with the chamber empty except for the clothing and bedding used, in order to ensure that these fabrics were not taking up or giving off water. A correction was applied to the results obtained on those occasions when a constant small difference was detected between the water content of the air entering and leaving the empty chamber, but the results were discarded when the difference was variable or large. A small plastic 
urine bag was secured to the baby's perineum before the start of each study; where the baby nevertheless soiled its napkin to any extent the results obtained were set aside because it could no longer be safely assumed that all the measured water loss represented evaporative heat loss from the baby itself. (Total evaporative water loss nearly doubled on the few occasions that the napkin became really wet.) Under these conditions recorded water loss was found to reach an equilibrium value within 30 minutes even in the presence of clothes and bedding.

Heated crib. Supplementary tests were also carried out using an open nursery cot provided with a small electric warming element below a mattress one centimetre thick having a thermal conductivity of approximately $3 \mathrm{kcal} . / \mathrm{m}^{2}{ }^{2} \mathrm{hr}$. ${ }^{\circ} \mathrm{C} . \mathrm{cm}$. These studies were conducted in a small draught-free air-conditioned room in which ward and nursery conditions could be simulated. The environmental conditions were monitored with a globe thermometer, hot-wire anemometer, and aspirating psychrometer, while body and cot temperatures were measured with a series of thermistor probes. Heat flow from the back of the hand was measured with a Hatfield heat-flow disc backed by a small water-jacket maintained at a constant temperature, in order to judge what conditions produced vasodilatation, while active sweating was detected by placing pieces of starch paper impregnated with iodine vapour on the skin. Heat production was measured in these studies by placing a light Perspex hood over the head of the baby as it lay in the cot and measuring oxygen consumption with a Kipp Diaferometer. The reliability of the equipment was tested at regular intervals with known gas mixtures, and the accuracy and constancy of the calibration factor also checked every fortnight by burning alcohol under the hood.

Statistics. Linear relations estimated statistically (by minimizing the squares of the perpendicular distances of the points from the line) have been represented as unbroken lines in the illustrations to this paper; lines and curves fitted by eye have been represented by pecked and dotted lines.

\section{Results}

Babies clothed and covered with blankets. The babies were dressed in a short woollen vest, a large towelling napkin, and a long cotton nightdress; they were lightly swaddled in a flannelette sheet placed on a thick linen-covered waterproof mattress and covered by two layers of cotton blanket (Fig. 1). 10 babies weighing between 2 and $3 \mathrm{~kg}$. at birth (mean $2.51 \mathrm{~kg}$.) were studied in detail when between 3 and 10 days old under conditions similar to those provided by a draughtfree room with a temperature of between 16 and $31{ }^{\circ} \mathrm{C}$. The results obtained are summarized in Fig. 2 and 3.

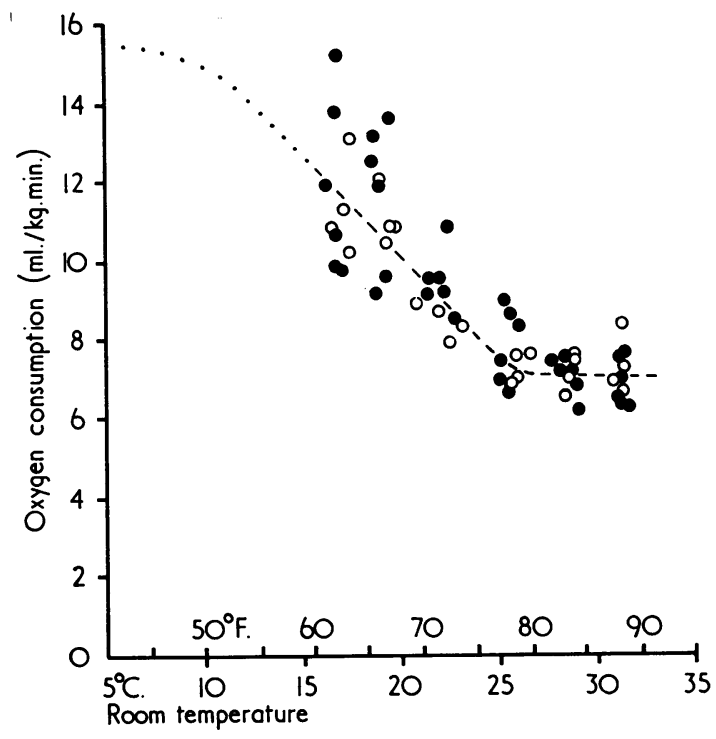

FIG. 2.-The oxygen consumption recorded in 10 babies weighing between 2 and $3 \mathrm{~kg}$. who were subjected to different simulated room temperatures while dressed and wrapped in blankets in the metabolic chamber shown in Fig. 1. The open circles represent measurements on babies who weighed less than $2.5 \mathrm{~kg}$. The pecked line has been drawn by eye, and the dotted extension is conjectural (see discussion).

High levels of oxygen consumption were found at low environmental temperature, and minimum levels when the environmental temperature was more than $25^{\circ} \mathrm{C}$. (Fig. 2). At the lowest temperature studied slight intermittent limb tremors were sometimes seen in babies that seemed to be asleep, but none of the infants cried or became restless even in an environment of $16^{\circ} \mathrm{C}$. and increases in muscular activity were only detected in 2 of the 4 infants who were studied electromyographically. Most of the babies appeared to be asleep the whole time even when the oxygen consumption was more than $50 \%$ above the level recorded in a warm environment.

Many of the babies had a slightly low rectal temperature when first collected for examination immediately after being fed, and body temperature often fell a little further while the babies were being weighed, dressed, and placed in the metabolism chamber, but rectal temperature remained constant or rose again once the babies were settled in the chamber even though the temperature was as low as $16^{\circ} \mathrm{C}$. Average rectal temperature at the start of the study was $36 \cdot 5^{\circ} \mathrm{C}$. (range $36 \cdot 1-$ $36.9^{\circ} \mathrm{C}$.) and the average rise observed during the hour spent undisturbed in an environment of $16^{\circ} \mathrm{C}$. 

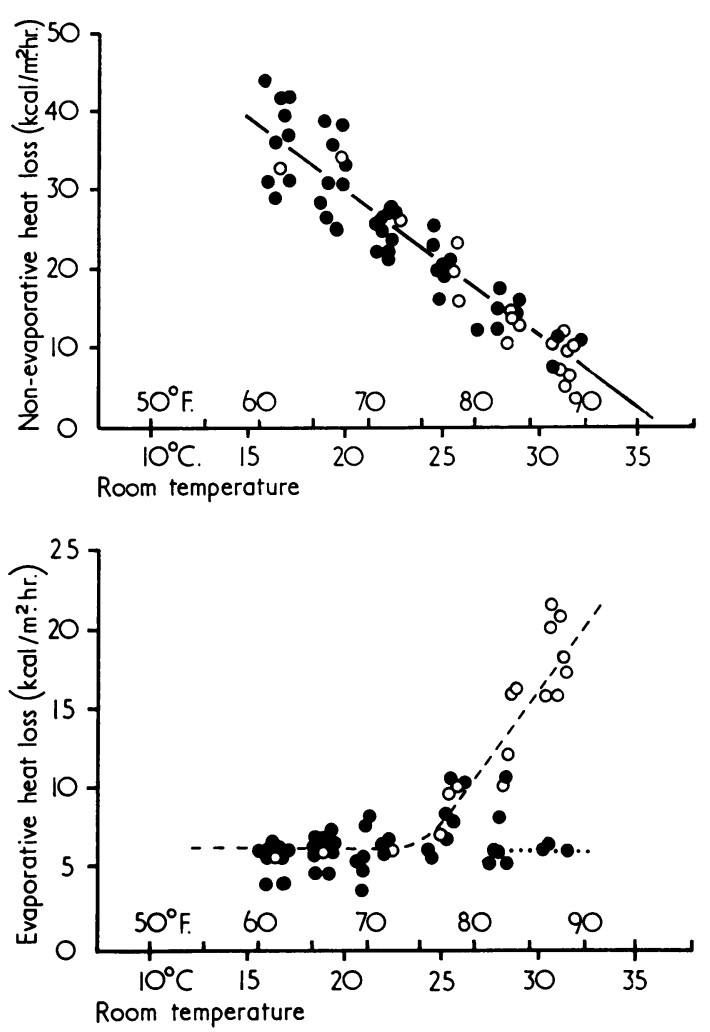

FIG. 3.-Total non-evaporative and evaporative heat loss when 10 cot-nursed babies weighing between 2 and $3 \mathrm{~kg}$. were subjected to different simulated room temperatures (note the expanded scale for evaporative heat loss). The open circles represent measurements taken when rectal temperature was more than $37 \cdot 2^{\circ} \mathrm{C}$.

was $0 \cdot 2^{\circ} \mathrm{C}$. Rectal temperature nearly always rose faster than this in the warmest environment studied $\left(31{ }^{\circ} \mathrm{C}\right.$.), but none of the babies became restless. Observations were discontinued before the rectal temperature reached $37 \cdot 8^{\circ} \mathrm{C}$. $\left(100^{\circ} \mathrm{F}\right.$.).

Estimates of total evaporative heat loss are summarized in Fig. 3. At low environmental temperature the loss was much the same as that found by Hey and Katz (1970) in their study of thermal balance in naked babies. The loss amounted to about three-quarters of a gram of water per $\mathrm{kg}$. body weight per hour and did not seem to be significantly affected by the presence of several layers of clothing. When the environmental temperature was high and the rectal temperature was above $37.2{ }^{\circ} \mathrm{C}$. total water loss increased significantly (Fig. 3), and sweat could be detected on the forehead and chest.
Three babies failed to start sweating during the hour they spent in an environment of $31^{\circ} \mathrm{C}$.: these babies initially had a low body temperature and, though rectal temperature rose during exposure to this warm environment, it had not exceeded $37 \cdot 2{ }^{\circ} \mathrm{C}$. by the time the measurements were taken. There can be little doubt that these babies would have started to sweat if the study had been prolonged for another hour.

Estimates of total non-evaporative heat loss are also summarized in Fig. 3. The relation took the expected form and was effectively linear despite the fact that these infants have been shown to vasodilate when the environmental temperature exceeds about $26^{\circ} \mathrm{C}$. This increase in skin blood flow caused a significant increase in total non-evaporative heat loss in the naked baby (Hey and Katz, 1970, Fig. 3) but caused little change in over-all heat flow in the cot-nursed baby because the insulation of the skin was small compared with the constant insulation afforded by the clothing, bedding, and still air (Table II).

Similar studies were undertaken on another 12 babies in order to establish the effect of birthweight on the relation established above. Fig. 4 shows the result obtained with two babies who weighed $1.3 \mathrm{~kg}$. at birth, and who were studied when between 3 and 5 days old: oxygen consumption and total heat loss only reached a minimum in these babies when the environment was above $29^{\circ} \mathrm{C}$. However, the relation between nonevaporative heat loss and environmental temperature had much the same slope as in the heavier babies, which suggests that total insulation was much the

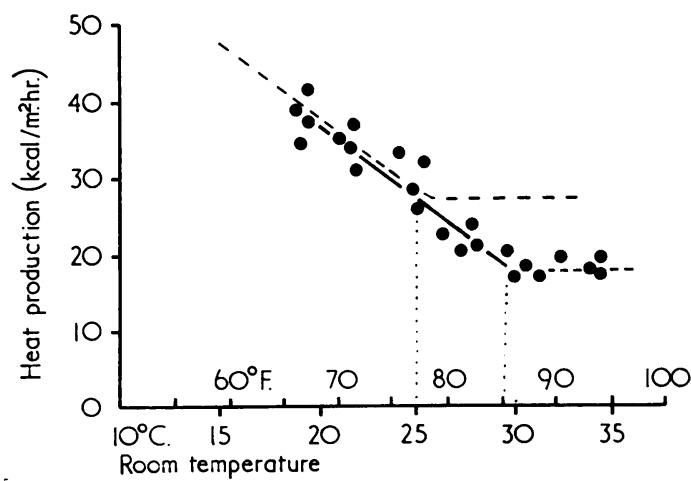

FIG. 4.-Heat production in 2 babies who weighed $1 \cdot 3 \mathrm{~kg}$. at birth. The babies were subjected to 6 different simulated room temperatures while dressed and wrapped in blankets when they were between 3 and 5 days old. The upper pecked line indicates the mean relation found in 10 babies who weighed between 2 and $3 \mathrm{~kg}$. at birth (from Fig. 2). 
same. Additional evidence that body size makes little difference to the effective insulation that cot nursing affords the newborn baby is summarized in Table I.

\section{TABLE I}

Total Non-evaporative Heat Loss in Babies 3-10 Days Old in a Draught-free Environment of $20^{\circ} \mathrm{C}$. $($ mean $\pm S E M)$

\begin{tabular}{|c|c|c|c|c|}
\hline \multirow{2}{*}{$\begin{array}{l}\text { Body Weight } \\
\text { in kg. } \\
\text { (mean and } \\
\text { range) }\end{array}$} & \multirow{2}{*}{$\begin{array}{c}\text { No. } \\
\text { of } \\
\text { Babies } \\
\text { Studied }\end{array}$} & \multirow{2}{*}{$\begin{array}{c}\text { Mean } \\
\text { Surface } \\
\text { Area } \\
\left(\mathrm{m} .^{2}\right)\end{array}$} & \multicolumn{2}{|c|}{$\begin{array}{c}\text { Heat Loss } \\
\left.\text { (kcal./m. }{ }^{2} \text { hr. }{ }^{\circ} \mathrm{C} .\right)\end{array}$} \\
\hline & & & Clothed & Cot-nursed \\
\hline $\begin{array}{l}1 \cdot 7(1 \cdot 5-1 \cdot 9) \\
2 \cdot 5(2 \cdot 0-2 \cdot 9) \\
3 \cdot 8(3 \cdot 0-4 \cdot 5)\end{array}$ & $\begin{array}{r}5 \\
10 \\
5\end{array}$ & $\begin{array}{l}0 \cdot 14 \\
0 \cdot 19 \\
0 \cdot 25\end{array}$ & $\begin{array}{l}38 \pm 2 \\
39 \pm 2 \\
37 \pm 1\end{array}$ & $\begin{array}{l}30 \pm 2 \\
31+1 \\
32 \pm 2\end{array}$ \\
\hline
\end{tabular}

The babies lay on a foam mattress. One group were lightly clothed; the other group were similarly clothed but also lightly swaddled in a sheet and covered with blankets. Body size has little effect on heat loss in these circumstances.

Clothed babies lying on a mattress. Similar studies were undertaken with 20 babies who were clothed but not provided with any bedding. The studies were carried out in the same metabolism chamber and the babies lay on the mattress dressed in a short woollen vest, large towelling napkin, and long cotton nightdress as before. 10 babies weighing between 2 and $3 \mathrm{~kg}$. at birth (mean $2.53 \mathrm{~kg}$.) were studied in detail when between 3 and 10 days old. Some of the results are summarized in Fig. 5. These babies started to increase their oxygen consumption when the environmental temperature was taken below about $28^{\circ} \mathrm{C}$., while sweating was detected when the environmental temperature exceeded about $30^{\circ} \mathrm{C}$. Several of the babies became overtly restless when the environmental temperature was less than $20^{\circ} \mathrm{C}$. Body size had little effect on the total resistance to heat loss displayed by these clothed babies (Table I).

Naked babies lying on a mattress. Similar studies were undertaken for comparative purposes on 10 naked babies who weighed between 2 and 3 kg. at birth (mean $2.49 \mathrm{~kg}$.) while they lay on a thick foam mattress in the large metabolism chamber. Evaporative water loss rose significantly when the environmental temperature was as high as $34^{\circ} \mathrm{C}$., while oxygen consumption and total heat loss both rose when the environment was less than $32^{\circ} \mathrm{C}$. Non-evaporative heat loss averaged $5.4 \mathrm{kcal} . / \mathrm{m} .{ }^{2} \mathrm{hr}$. per degree temperature gradient (see Fig. 7), and conductive heat loss direct to the mattress accounted for only about $6 \%$ of this loss.

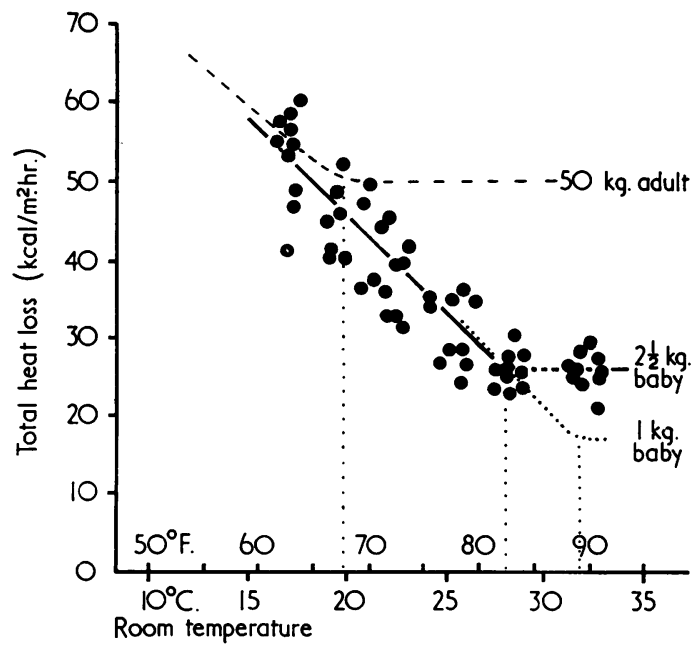

Fig. 5.-Total heat loss when 10 babies weighing between 2 and $3 \mathrm{~kg}$. lay clothed on a cot mattress but were not covered with a blanket or swaddled in any way. These babies increased their heat production when simulated room temperature fell below $28^{\circ} \mathrm{C}$. The pecked line shows by comparison the result to be expected in an adult wearing an equivalent amount of clothing. A small $1 \mathrm{~kg}$. baby would, in contrast, be expected to behave in the manner shown by the dotted line when a few days old.

These results are in good agreement with the estimates given by Hey and Katz (1970) on the basis of work conducted in the original small metabolism chamber. Calculations based on a knowledge of equilibrium mean skin temperature (Hey et al., 1970) show that the body tissues themselves account for less than one-third of the naked baby's total resistance to heat loss (Table II).

Use of heating element below mattress. Further supplementary studies were undertaken with the babies clothed and covered as before using an open nursery cot and a Diaferometer in a temperature-controlled room. The results confirmed the validity of the general relation between oxygen consumption, heat balance, and room temperature already established using the metabolic chamber. In 10 babies 3 to 10 days old with a mean weight of $2.46 \mathrm{~kg}$. studied in an unheated cot average total heat loss was $36 \mathrm{kcal} . / \mathrm{m} .{ }^{2} \mathrm{hr}$. in a room at $20^{\circ} \mathrm{C}$. If allowance is made for an evaporation loss of about $6 \mathrm{kcal} . / \mathrm{m} .{ }^{2} \mathrm{hr}$. this result is in good agreement with the results obtained in the metabolism chamber (Table I). Measurement of heat loss from the hand suggested that all the babies were vasoconstricted. 
TABLE II

Resistance to Heat Loss in clo Units for a Baby Weighing $2.5 \mathrm{~kg}$. Lying on a Foam Mattress in a Cool Draught-free Environment

\begin{tabular}{l|c|c|c}
\hline & Naked & Clothed & Cot-nursed \\
\hline Effect of body tissue & 0.29 & 0.29 & 0.29 \\
Effect of still air & 0.78 & 0.78 & 0.78 \\
Effect of clothing & - & 1.25 & 1.25 \\
Effect of bedding & - & - & 0.61 \\
\hline Total resistance & 1.07 & 2.32 & 2.93 \\
\hline
\end{tabular}

The effectiveness of using the small electric warming element below the mattress was also examined. When the warming element was adjusted to maintain the base-plate below the mattress at $46^{\circ} \mathrm{C}$. for 3 hours, body temperature rose by an average of $0.4^{\circ} \mathrm{C}$. to $37 \cdot 1{ }^{\circ} \mathrm{C}$, and 7 of the 10 babies vasodilated. Oxygen consumption (Fig. 6) and heat loss both fell. Average total heat loss in the third hour was $29 \mathrm{kcal} . / \mathrm{m} .^{2} \mathrm{hr}$.

\section{Discussion}

Response to cold stress. A naked baby soon cries and becomes active when exposed to a cold environment. In surroundings cold enough to increase heat production by $50 \%$, few naked babies sleep for more than a few minutes at a time. In contrast, almost all the swaddled infants exposed to an environment cold enough to provide a comparable increase in heat production continued to sleep quietly. This tranquillizing effect has also

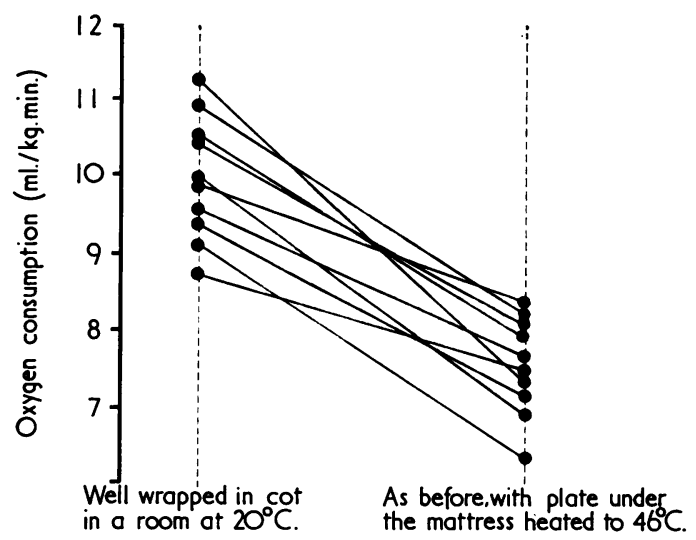

Fig. 6.-The effect of extra heat from a warm plate below the mattress on oxygen consumption in 10 cot-nursed babies weighing between 2 and $3 \mathrm{~kg}$. who were clothed and covered with blankets in a room at $20^{\circ} \mathrm{C}$. been commented on by Mestyán, Járai, and Fekete (1968). The ability of the baby to increase its: heat production to this extent in the absence of ${ }^{2}$ overt muscular activity provides strong confirma-o tory evidence for the role of non-muscularo thermogenesis.

When a naked baby is exposed to a cold environment, the rise in heat production is seldom sufficient to prevent some fall in rectal temperature. $A_{-}^{\mathcal{E}}$ response of this kind often occurs even when the. cold stress is relatively mild, despite the fact that the $\overrightarrow{-}$ baby is demonstrably capable of increasing its heat $\omega$ production enough to maintain a constant deep body temperature (Hey, 1969). When, in contrast, ? clothed or cot-nursed babies were exposed toct equivalent cold stress, rectal temperature rose. This finding is in keeping with other experimental evidence in suggesting that the face and upperc్ respiratory tract are particularly receptive to thermal stimuli.

It is known that babies are seldom capable of ${ }_{C}^{-}$ increasing their heat production more than $150 \%$ in the first two weeks of life (Hey, 1969), and this $\bar{D}$ is the justification for the dotted extrapolation of $\overrightarrow{0}$ the graph in Fig. 2 at low environmental tempera- -0 ture. The studies reported here show that this upper limit to heat production will be reached in the average full-term cot-nursed infant when room temperature falls to about $10^{\circ} \mathrm{C}$. $\left(50^{\circ} \mathrm{F}\right.$.). Many bedrooms get colder than this at night in winter, $\frac{\alpha}{\infty}$ and babies readily become hypothermic in these circumstances. A healthy $1.5 \mathrm{~kg}$. baby has a lower minimum and maximum heat production per unit surface area, and the temperature limit may be nearer to $15^{\circ} \mathrm{C}$. $\left(60^{\circ} \mathrm{F}\right.$.). It is particularly important to note that these swaddled babies may not cry or otherwise call attention to the fact that? they are under severe cold stress.

Comparative warmth. An idea of the magnitude of the several factors contributing to the ? baby's total insulation against heat loss can be gained from Table II. In draught-free conditions the boundary layer of still air round the baby provides twice as much insulation as the body ? tissues themselves, even when the skin is vaso- $N$ constricted. This result emphasizes the import- N ance of protecting any inadequately clothed baby 0 from draught. Normal clothing increases the total insulation by 1.25 units, while the addition of $\frac{}{0}$ a flannelette sheet and two layers of cotton blanket $\stackrel{\oplus}{?}$ only increases total insulation a further 0.6 units. $T$ It is probable that further insulation could be $\overrightarrow{0}$ achieved by covering the baby's head with a bonnet, $\stackrel{\mathbb{D}}{\circ}$ but it is clear that the effectiveness of adding 


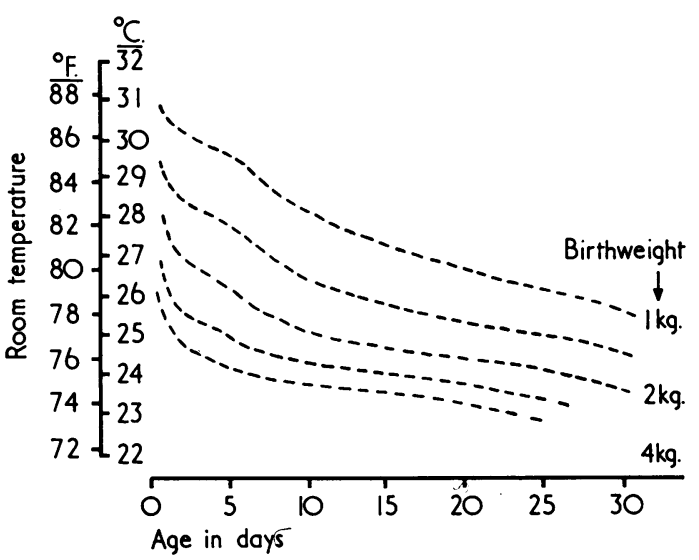

FIG. 7.-Estimates of the room temperatures to provide a cot-nursed baby with conditions of optimum warmth during the first month of life. The mean temperatures shown are appropriate for a baby in draught-free conditions clothed and wrapped in blankets (combined insulation $1.9 \mathrm{clo}$ ). The 'optimum' temperature was assumed to be the minimum room temperature to provide conditions of strict thermal neutrality, estimated in the manner outlined in the preceding paper (Hey andKatz, 1970).

further blankets to the cot is likely to be marginal.

The increased insulation afforded to a cotnursed baby lowers the environmental temperature necessary for reasonable warmth. An environment of rather more than $32^{\circ} \mathrm{C}$. is necessary to provide real warmth for a naked baby weighing between 2 and $3 \mathrm{~kg}$. at birth during the first 10 days of life (Hey and Katz, 1970). When such a baby is clothed but not covered by any bedding, heat production increases when room temperature falls below about $28^{\circ} \mathrm{C}$. (Fig. 5). In this respect the present results are in accord with the data on clothed babies obtained by Pribylová (1963) and Prribylová and Znamenáček (1964), though the absolute values for heat production recorded by these authors are inexplicably low. When such a baby is nursed fully clothed in a cot, oxygen consumption (Fig. 2) and evaporative water loss (Fig. 3) are both at a minimum when the room temperature is $25^{\circ} \mathrm{C}$., and this, then, is the temperature to provide what may be termed a 'neutral thermal environment'.

Over-all insulation against heat loss is very little affected by birthweight (Table I), but heat production in an environment free of thermal stress is very considerably affected by birthweight and also influenced by age (see Hey and Katz, 1970, Fig. 1). In consequence a room temperature in excess of $25^{\circ} \mathrm{C}$. may be necessary to provide a cot-nursed baby with true thermal neutrality in the first few days of life, and this is particularly true of babies weighing less than $2 \mathrm{~kg}$. at birth (Fig. 7). Mestyán et al. (1965) studied a group of swaddled babies who weighed less than $2 \mathrm{~kg}$. at birth, and came to the conclusion that a nursery maintained at between 22 and $26^{\circ} \mathrm{C}$. failed to provide neutral conditions for these babies in the first month of life. When really small babies are nursed in a cot, a temperature of $30^{\circ} \mathrm{C}$. may be necessary to provide complete thermal neutrality (Fig. 7).

This change in the relation between heat balance and environmental temperature with age and size is also illustrated in Fig. 5. Here the individual results plotted relate to 10 clothed babies who weighed between 2 and $3 \mathrm{~kg}$. at birth and who were studied when between 2 and 10 days old. A small baby the same age but weighing only $1 \mathrm{~kg}$. would, in contrast, be expected to behave in a manner shown by the dotted line in Fig. 5, while the result to be expected in an adult walking about and wearing an equivalent amount of clothing is shown by the pecked line. In these circumstances an adult feels comfortable and warm in a room with a temperature down to $19^{\circ} \mathrm{C}$. (Hickish, 1955): only below this temperature does the adult need to generate extra heat in order to maintain body temperature. It is clear therefore that a room that is intolerably warm for an adult may be unduly cold for a small baby wearing an equivalent amount of clothing, and it is not surprising that many babies become cold when they are picked up out of their cots to be fed. The differences are largely due to changes in basal heat production and the position largely corrects itself over the first 3 months of life, since by this age most babies are generating as much heat per unit area under basal conditions as adults, and sometimes rather more (Lee and Iliff, 1956).

The studies with the Diaferometer and open cot have provided confirmatory evidence that the environment within the metabolic chamber adequately simulated that provided by a cot in an open ward. They have also served to show that a heated crib can provide a small baby with valuable extra warmth. The cot studied was capable of providing as much extra warmth as would have been achieved by raising the room temperature $5^{\circ} \mathrm{C}$., or by adding three-quarters of a clo unit to the total insulation provided against heat loss, but it is important to note that the amount of heat provided by such a system is dependent on the size and thickness of the mattress through which the heat has to be conducted. Both the baby and the surrounding bedding gain heat from the mattress; for the condi- 
tions under study it could be shown that about onethird of this heat was effective in decreasing the baby's own need to produce heat.

Practical implications. In the final illustration we have summarized our findings on babies weighing 2 to $3 \mathrm{~kg}$. when between 3 and 10 days old (Fig. 8). The figure indicates the range of environmental temperatures over which an infant could be expected to maintain its rectal temperature between 36.5 and $37.5{ }^{\circ} \mathrm{C}$. for a reasonable length of time, and the levels of heat production necessary. Neutral thermal conditions are provided by an operative temperature of $32.5^{\circ} \mathrm{C}$. when naked, and $25^{\circ} \mathrm{C}$. when well wrapped up in a cot.

The figure also shows, graphically, another extremely important difference between the environment provided for a naked baby in an incubator and that provided for a clothed baby in a cot. Should the temperature within the incubator fall $2{ }^{\circ} \mathrm{C}$., heat production would need to increase more than $35 \%$ for there to be no fall in deep body temperature; should it rise $2{ }^{\circ} \mathrm{C}$., the baby would become pyrexial even if it sweated more than average (Hey and Katz, 1970, Fig. 2). Similar fluctuations in room temperature would have a negligible effect on a clothed baby in a cot; room temperature would have to fall to $19^{\circ} \mathrm{C}$. or rise to $31^{\circ} \mathrm{C}$. to have a comparable effect on a clothed baby under blankets in a cot.

It seems reasonable to nurse such a baby naked

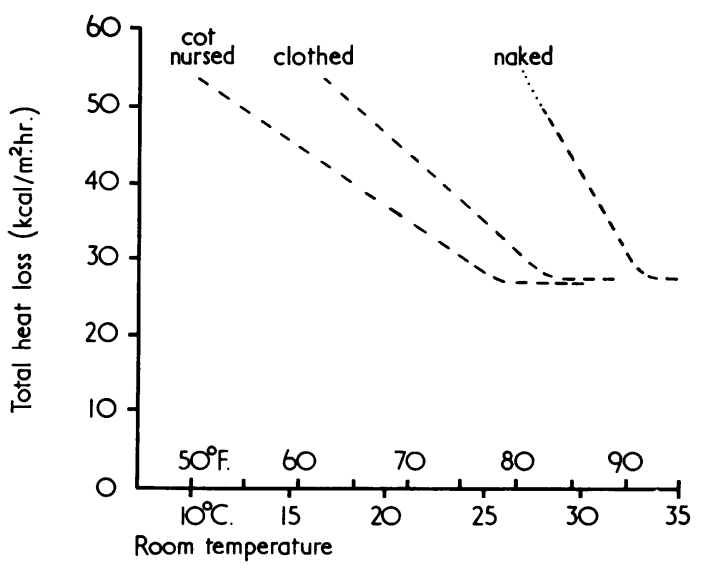

FIG. 8.-The relation between heat loss and room temperature in a typical baby weighing between 2 and $3 \mathrm{~kg}$. when more than 2 days old. Clothes and bedding increase the resistance to heat loss and decrease the temperature necessary to provide thermoneutral conditions. in an incubator with an operative temperature close $\frac{\rho}{\overline{\frac{\rho}{3}}}$ to $32^{\circ} \mathrm{C}$. $\left(90^{\circ} \mathrm{F}\right.$.) if it is important to keep the? child under continuous observation. Close control $\overrightarrow{\vec{F}}$ needs to be maintained over incubator temperature because changes of as little as $1^{\circ} \mathrm{C}$. $\left(2^{\circ} \mathrm{F}\right.$.) will등 have a marked effect on thermal balance. In other $\overline{\bar{c}}$ circumstances, where the baby is not under con- $\bar{\phi}$ tinuous observation, adequate and reasonably $\frac{\varrho}{0}$ constant warmth can probably be more easily, $\infty$ cheaply, and safely provided by nursing the baby $\vec{O}$ clothed and lightly wrapped in a warm room at a $\overrightarrow{-}$ little over $24^{\circ} \mathrm{C}$. $\left(75^{\circ} \mathrm{F}\right.$.).

The same argument applies with equal force to even smaller babies. However, in these babies a cot may no longer provide optimum warmth unless $f$ heating is provided below the mattress or the roomin

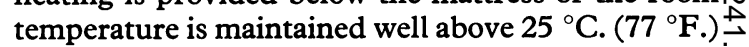
and this can be rather uncomfortable for the atten- $-\omega$ dants unless they change into light clothing when o working in the nursery. There may be a case for 을 returning to the practice of nursing some tiny $1 \mathrm{~kg}$. $\vec{c}$ babies lightly clothed in an incubator at a little $\stackrel{\complement}{=}$ over $31^{\circ} \mathrm{C}$. $\left(88^{\circ} \mathrm{F}\right.$.) when they are no longer under $\widetilde{\sigma}$ continuous observation, since the provision of $\vec{\omega}$ clothing helps to minimize the effect of any fluctua- $-\vec{\partial}$ tion in environmental temperature.

The present study has served to confirm the correctness of the clinical criteria on which Budin (1900) and Blackfan and Yaglou (1933) judged the selection of optimum air temperature for their $\frac{\not}{\mathrm{D}}$ cot-nursed babies. There is, as yet, little convinc- $\varrho$ ing evidence that the current cult for nursing many $\overrightarrow{\overrightarrow{0}}$ babies completely naked has improved on the 3 standard of nursing care that was pioneered by these clinicians.

We are grateful to Professor K. W. Cross for en-? couragement and advice, and wish to acknowledge the $\frac{\sigma}{3}$ skill and help of Mrs. Jill Freeman, S.R.N., R.S.C.N., and Miss Margaret Burton, S.R.N., with the studies $\delta$ reported here and their analysis. We wish to thank the of The London Hospital, without whose consent, $\frac{\text { ? }}{\supset}$ interest, and help this work would not have been possible. $D$

The large metabolic chamber was made in the Medical 0 and Dental School Workshops by Mr. J. Young and Mr. P. Richards. The Kipp-Noyons Diaferometer was $\mathrm{N}$ made available by Dr. G. Graham and the Thoracic Unit at The Hospital for Sick Children, Great Ormond $O$ Street, and the electrically heated crib was lent to us by Dr. V. Smallpeice and Dr. D. Hull.

\section{REFERENCES}

Blackfan, K. D., and Yaglou, C. P. (1933). The premature infant. \& A study of the effects of atmospheric conditions on growth and + on development. American fournal of Diseases of Children, 46, 1175.

Budin, P. (1900). Le Nourrisson. O. Doin, Paris. Translation $\stackrel{+}{\square}$ by $W$. Maloney (1907). The Nursling, pp. 1-18. Caxton, London. 
Gagge, A. P., Burton, A. C., and Bazett, H. C. (1941). A practical system of units for the description of the heat exchange of man with his environment. Science, 94, 428.

Hey, E. N. (1969). The relation between environmental temperature and oxygen consumption in the new-born baby. Fournal of Physiology, 200, 589.

, and Katz, G. (1970). The optimum thermal environment for naked babies. Archives of Disease in Childhood, 45, 328.

, - and O'Connell, B. (1970). The total thermal insulation of the new-born infant. Fournal of Physiology, 207, 683

Hickish, D. E. (1955). Thermal sensations of workers in light industry in summer. A field study in Southern England. fournal of Hygiene, 53, 112.

Hill, J. R., and Rahimtulla, K. A. (1965). Heat balance and the metabolic rate of new-born babies in relation to environmental temperature; and the effect of age and of weight on basal metabolic rate. fournal of Physiology, 180, 239.

Lee, V. A., and Iliff, A. (1956). The energy metabolism of infants and young children during postprandial sleep. Pediatrics, 18, 739.
Mestyán, J., Fekete, M., Bata, G., and Járai, I. (1965). A környezeti hömérséklet és koraszülöttek fenntartási kalóriaszükséglete az extrauterin élet elsö hónapjäban. Gyermekgyógyászat, 16, 44.

-, Járai, I., and Fekete, M. (1968). The total energy expenditure and its components in premature infants maintained under different nursing and environmental conditions. Pediatric Research, 2, 161.

Přibylová, H. (1963). Einfluss der Umwelttemperatur auf den Sauerstoffverbrauch, auf die Körper- und Hauttemperztur und die Atmung der reifen Neugeborenen. Annales Paediatrici, 201, 399.

, and Znamenácek, K. (1964). Some aspects of thermoregulatory reactions in newborn infants during the first hours of life. Biologia Neonatorum, 6, 324.

Correspondence to Dr. B. O'Connell, Department of Paediatrics, The London Hospital, London E.1. 